GHANA JOURNAL OF DEPARTMENT OF HEALTH, PHYSICAL EDUCATION AND RECREATION, SPORTS AND DANCE (GJOHPERSD)

Volume 7 \& 8, Year 2014 \& 2015

A JOURNAL OF THE DEPARTMENT OF HEALTH, PHYSICAL EDUCATION AND RECREATION (HPER)

UNIVERSITY OF CAPE COAST

GHANA, WEST AFRICA 


\title{
RECONCILING MENTOR AND RESIDENCE LECTURER'S SCORES IN GRADING STUDENTS ON TEACHING PRACTICE TO BE TRUE REFLECTION OF STUDENTS' PERFORMANCE
}

\author{
Charles Domfeh \\ Department of Health, Physical Education and Recreation \\ University of Cape Coast, Ghana \\ cdomfeh@ucc.edu.gh
}

\begin{abstract}
With the increasing number of students who qualify and enroll in universities the world over, and also in the various faculties and colleges of education studies, where students-teachers are trained for the teaching profession, it has become obvious that resident university teachers alone are unable to give ample supervision and monitoring to student-teacher trainees who go out of the campuses to experience real teaching practice. This is often referred to, as external or out of campus teaching practice. In trying to find solution to this vacuum created by insufficient lecturers, not being able to give enough supervisions and assessment scores to grade the practicing teachers, tutors or individuals in the various localities and/or institutions where the student-teachers do the external teaching practice are contracted by the universities as either mentors or internal supervisors to take oversight responsibilities of the student teachers formation, alongside the university lecturers, termed as external supervisors. This paper seek to find out how to reconcile the grading scores of the mentors or internal supervisors which at times, is often on the high side, as against the lecturers or external supervisors scores in order to reflect the true performance levels of the student teachers. This paper also lines up some suggested solutions to the dilemma in order to reflect the real students' performance scores.
\end{abstract}

Keywords: Teaching Practice, Student teachers, Supervision, Assessment Scores

A Journal of the Department of Health, Physical Education and Recreation 160 


\section{Introduction}

This paper intends to look at how to reconcile the dilemma of mentors' scores and university supervisors' scores for studentteachers, during teaching practice in order to get the true reflection of their performance, growth and development.

\section{Concepts of Teaching Practice}

Teaching practice requires a philosophy to give directions to values and actions. The philosophy is needed for the development of a reflective and reflexive learner who learns through situational analyzing, theorizing, hypothesis-testing, inquiring, experimenting, and justifying. Such development has to be built around the searching and identification of oneself as a teacher based on one's personal theory of teaching and learning. While supervisors can help by engaging in dialogues and interrogation with student teachers, they need also to carry out a personal reflection on their own self as a person of feelings, emotions, values and beliefs so as to embark on a transformation of their vision of what sort of teachers they would like to be.

Teaching practice programme in teacher education is implemented differently at different universities. Different models are applied depending on different national, regional and local contexts (Ure, 2009). Even if they overlap, different models can be identified. They emphasize different ideas, aspects and qualities. They have different historical roots and they represent different views on how professional practice knowledge is best nurtured. Different resources are allocated in terms of people, time, equipment and economy. Curricula differ and the procedures for assessing professional practice knowledge also differ. Sometimes the mentor or the university supervisor has a final say about student teachers who may pass or fail based on the final scores to use for grading. Often these decisions are taken by university based teacher educators. Teaching practice is generally part of a particular educational system and should be discussed in relation to that specific system. 
Reconciling Mentor and residence Lecturer's scores in grading Students on Teaching Practice to be true reflection of Students' Performance

Teaching practice in schools is considered to be a significant component of pre-service teachers' education

programme (Wilson, 2006) and highly valued by student teachers (Beck \&Kosnik, 2002). The practical teaching experiences help student teachers develop a contextualised understanding of the intricacies of teaching and provide an opportunity to develop competencies across a range of areas including classroom management skills, the fundamentals of lesson planning, awareness of personal teaching style, and the ability to interact with students. Furthermore, it helps in bridging the gabs between theories learnt in class and practical disposition of teaching profession which is the essential aspect of teacher preparation. Teaching practice experiences offer teacher students a place to observe and work with real students, teachers, and curriculum in natural settings.

However, the aim of teaching practice varies, depending on the view of teacher education which can be seen as cultural practices that serve local needs (Allen \& Peach, 2007). The credits allocated for teaching practice varies from institution to institution with the minimum being six credits which least for a semester. This represents an integral part of teacher training to become a teacher. The single objective for teaching practice is to equip student to responsibly and competently pursue students' future role as the educator of the future leaders. The Triad

The main personnel involve in this programme are the student teacher, the mentor and university supervisor. Each of them has a key responsibility which when effectively discharged will contribute to programme success. The major responsibilities of the mentors and the university lecturers are to combine two roles: as assessors and as supervisors. As supervisors, they are expected to observe how student teachers prepare, deliver the lesson and conduct themselves as members of teaching profession and are expected to advise the students on how to improve their teaching skills. As assessors, they are expected to evaluate and assign scores to student teachers based on how they performs in respect to the goals and standards of the programme. Authentic 
assessment evokes grounded theory which gives insights into teaching processes (Morse, 2003).

Every teacher preparation and development institution has a working handbook which clearly outlines the criteria for selecting a university supervisor and the mentor as well as the roles and responsibilities of the triad. The handbook further states clearly how to systematically supervise and assess students and the percentage of scores from the mentor and the university supervisor that contribute to the final grading of the student teachers. These roles and responsibilities are expected to be discharged diligently with unity and understanding for effective professional preparation and development of student teachers.

\section{The Dilemma}

Aside the clear definition of roles and responsibilities of triad outline in teaching practice supervision of student teachers, there are some criticisms about whether the mentors' scores or the university supervisors' scores should be used for final grading of student teacher for professional development (Smith, 2010; Haigh \&Tuck, 2000). This is because there is widespread dissatisfaction with the discrepancies of mentor scores and university supervisors' scores usually presented for grading student teachers (Mattsson\&Rorrison, 2011). Furthermore, Mattsson and Rorrison (2011) noted that many problems surrounding assessment practices arise. Out of an inability to reconcile these scores for sanity in grading student teachers as true reflection of their performance in order to achieve the goals of teaching practice programme.

\section{How to Reconcile Dilemma of Mentor's and University Lecturer's Scores for true Reflection of Student teachers Performance}

\section{Adopting the Student Internship Programme}

Having realized the above dilemma and its ardent effects on student teachers professional preparation and development some teacher training universities worldwide including University 
Reconciling Mentor and residence Lecturer's scores in grading Students on Teaching Practice to be true reflection of Students' Performance of Education, Winneba (UEW) have rolled over the Student Internship Programme (SIP) which is also known as mentorship programme that clearly gave the highest power of scoring student teachers by mentors whose scores form about $70 \%$ of the final grading of students during internship for true reflection of student teachers professional growth and development. With these criteria, both mentors and university supervisors know their responsibilities and will plan how to supervise and assess student teachers in accordance with their stipulated roles and responsibilities. Anderson (2007) argued that pre-service teachers are influenced by mentors through evaluations, rewards, distribution of knowledge, vested authority and charisma. As a result of this coercive power through evaluation, some student teachers may change their behaviour to gain favourable scores from their mentors. In this case the single score of university supervisor will be used by the final grading body to authenticate or verify the scores from the mentors before using the best method to derive at the final grade for the student teacher.

\section{Dual Function of University Supervisors}

The challenge of conceptualizing the teaching practice goes hand in hand with the challenge of re-conceptualizing the supervision of student teachers. Ideally, the teaching practice should be an opportunity for teacher educators and experienced school teachers to partner with each other in supporting and supervising student teachers (Starkey \& Rawlins, 2012). In reality, this is seldom the case and this results in inadequate supervision especially by the university supervisors and for that matter dilemma of whose scores to use for grading. Another issue is that some mentors who are not trained too do not have the needed experience to supervise and assess student teachers effectively as the true reflection of their performance.

Other activities also take the mentors away from being with the mentee. With all these issues, it is also noted that the supervision which did exist seldom involved supervisors helping students make connections between theory and practice. Similarly, 
Anderson (1997) describes the situation as even worse in Malawi where supervision is "substandard, if indeed, it takes place at all"

To reconcile this dilemma, there is the need for empowering the mentor teacher with the responsibility for the training of the student teacher. The mentor teacher in turn would be supported by the university supervisor whose role would be focused on providing liaison teacher education between the teacher training institutions and the schools. This reconceptualization of supervision would ensure that supervision stand out separate from assessment which is another function of the supervisors (Smith, 2007). In that effect there will be mutual agreement as to which score to use in grading student teachers teaching for true reflection of their performance.

\section{Method of Assessing Student Teachers Teaching}

Arguably, the best form of assessment of student teacher's teaching for professional development is formative assessment. However, summative assessment also serves as a gate keeping function, which is suitable for selection of student teachers in order to protect the profession from incompetence (Smith, 2010). Smith (2006) has discussed the various roles of assessment in teacher education, and she claims that the two contradicting functions, the formative and the summative, the feed-forward and the judgmental role, increase in complexity when both functions of assessment are carried out by the same person. It can be stressful to have the role of supporter and judge at the same time, even though the final decision is placed with the university. Smith's (2006) argument point to the fact that assessment of teacher's teaching is a complex issue and the dilemma relating to the scores to be used for grading can be reconciled through the use of formative assessment technique. By so doing, the trend of scores about student teaches performance can predict the progress of score to use for the final grading of student teacher's teaching. With the data available, the stakeholders can verify the reliability of the grade to ascertain whether it's the through reflection of the student teacher's 
Reconciling Mentor and residence Lecturer's scores in grading Students on Teaching Practice to be true reflection of Students' Performance performance during the course of professional growth and development.

\section{Parallel Assessment of Student Teachers Teaching by Mentors and University Supervisors}

Another way to reconcile this dilemma is encourage parallel assessment of student teachers' teaching by mentor and university supervisor. The two supervisors need to student teachers teaching at least two lessons after agreeing on what to look for during observation using the agreed observation instrument during the pre-observation conference. During the post- observation conference the mentor and university lecturer will compare their rating and make the necessary adjustment for accurate and reliable observation and feedback. This will bring about inter-rater reliability in scoring student teacher's teaching (Yarling\& Wentz,1994). Further discussion of performance by the triad during the post-teaching conference will harmonize and increase objectivity of scoring the student teachers which makes team score during parallel teaching as a true reflection of student teachers performance for professional growth and development.

\section{Use of Average Mean Score for Grading}

Finding the average mean of scores from university lecturer and that of the mentor will reconcile the dilemma in grading student teachers during teaching practice for true reflection of student teachers performance for professional development. According to Kothari and Garg (2014, p. 129) mean is the most common measure of central tendency and useful for summarizing scores collected by different people or at different times.

Mentors and university supervisors should be encouraged to gather more scores about student teachers teaching. This will later show the trend of student teachers' performance in regards to professional growth and development. In that effect, when this data is submitted for final grading, the consistency in data from the mentor or the university supervisor will help come out with the 
best modality to use in reconciling the dilemma of mentor's scores and university lecturers' score in grading of student teachers' on

teaching practice in order to bring about the true reflection of their performance for professional growth and development.

\section{Use of Qualified Mentors and University Supervisors}

Qualified and trained mentors and university supervisors who are specialist in the student teachers subject areas are better will be better supervisors and assessors if trained in addition. To be supervise and assessor of student teachers' teaching and give contextual and content-related feedback, there is the need for a mixture of subject content knowledge and pedagogical content knowledge and skill for effective scoring and feedback (Stark \& Rawlins, 2011).

Mentors and university supervisors who are not in the area of student teacher's subject area of teaching may not be able to give accurate feedback on students teaching due lack of content and pedagogical knowledge. As a result, the scores from such assessors may not valid and reliable due lack of content and contextual congruence. In that case, the university supervisors' scores should be used for grading the student teachers' teaching as the true reflection of their performance for professional development.

\section{Plan Supervision and Assessment of Student Teacher's Teaching}

Planning is the most important key to success. Failing to plan is planning to fail. After the supervisor has gathered adequate information on teacher characteristics and instructional context, he or she then makes specific plans for the lesson observation. If teachers' developmental stages, characteristics, and instructional contexts can vary, so too should observational strategies. No single observation strategy can work well in every situation; thus, the supervisor must make important decisions to prepare for the observation.

The mentor or the university supervisors need to plan ahead of time and inform the student teacher especially about your intended 167 A Journal of the Department of Health, Physical Education and Recreation 
Reconciling Mentor and residence Lecturer's scores in grading Students on Teaching Practice to be true reflection of Students' Performance scheduled for supervision and assessment as well as achievement goals. This prior notice can prevent low performance of student teacher on the bases of inadequate preparation as well as the mentor or university supervisor from doing shallow supervision or assessment and scoring the student teacher's teaching for grading. With this approach, together with content-related feedback, we will reduce the dilemma of which scores to use for grading of student teachers' teaching practice due the planned and systematic nature of the process.

\section{Congruence of Feedback with Assessment Scores}

Feedback is another concept whose importance in the instructional encounter (Smith, 2010), the meeting point between learning, teaching and assessment, is becoming a major issue in research on assessment for student teachers' teaching (Smith, 2007). Feedback is currently seen as the heart of supervision and assessment for learning. Feedback is one of the most powerful influences on learning and achievement, but this impact can be either positive or negative (Hattie \& Timperley, 2007). Quality of feedback is not just the structure of the feedback but also its accessibility to the learner, its catalytic and coaching value, and its ability to inspire confidence and hope (Sadler, 2009). Useful feedback which carries a positive impact on students' learning is not just a grade or a general statement to the learner, but as detailed meaningful information essential to the learner and the supervisor when planning future steps in the learning process.

According to Hattie and Timperley (2007) feedback serves multiple functions. First, it is a kind of careful description of the current status of learning based on performance. The student becomes aware of strengths and weaknesses by engaging in dialogue with the mentor or supervisor. Second, it reduces the discrepancy between current knowledge and the learning goal and improves teaching performance. There are two actors in this process, the supervisor and the student. The latter needs to be open to receive and accept feedback, and he/she needs to know how to apply it when planning and executing future performances. 
In the light of this, the congruence of mentor feedback with the assessment scores or the university supervisors feedback with assessment scores of the student teachers' teaching demonstrate how valid and reliable the scores are for grading student teacher teaching as a true reflection of performance for professional development. On the face of this, the assessor whose feedback is most congruence with the scores should be used for grading student teachers' teaching.

\section{Avoiding or Scaling down the Scores which are on the Extreme}

Assessors whose scores for students are far lower or extremely high on the average from the rest of the supervisors, it is scaled down to reflect the average scores the other supervisors have awarded. In cases where the minimum supervision requirements would be met without the extreme scores, such scores are expunged in other to avoid influencing the true reflection of such teacher.

\section{Conclusion}

The success of teaching practice supervision rest in the hands of the stakeholders, who are to ensure that their roles and responsibilities are effectively discharged. The dilemma of scores from the mentors and university supervisors come as a result of negligence of duty, lack of qualified mentors and mentorship training as well as dual function of supervisors. When the dilemma concerning mentors and university supervisor's scores for grading student teachers 'teaching are not resolved then the preparation and development of student teachers is in total jeopardy. To avoid all these dilemma, the supervision handbook should spell out clearly who scores should be used for grading student teachers' teaching. This will provide everlasting solution to the dilemma of scores from the mentors and university supervisors in grading student teachers teaching for objectivity and as the true reflection of their performance for professional growth and development. 
Reconciling Mentor and residence Lecturer's scores in grading Students on Teaching Practice to be true reflection of Students' Performance

\section{References}

Anderson, D. (2007). The role of cooperating teachers' power in student teaching. Education, 128, 307-323.

Anderson, L.W. (1997). Teacher preparation for post-modern schools: The necessary integration of training and education. In W.K. Cummings \& N. F. McGinn (Eds.). International handbook of education and development: Preparing schools, students and nations for the 21 st century. Oxford: Pergamon.

Beck, C., \& Kosnik, C. (2002). Components of a good practicum placement: Student teacher perceptions. Teacher Education Quarterly, 29(2), 81-98.

Hattie, J.,\& Timperley, H. (2007). The power of feedback. Review of Educational Research, 77(1), 81-112.rH

Kothari, C. R., \& Garg, G. (2014). Research methodology: Methods and techniques (3rd ed.). India: New Age International (p) Ltd.

Sadler, D. R. (2009). Indeterminacy in the use of preset criteria for assessment and grading in higher education. Assessment and Evaluation in Higher Education, 34, 159-179.

Smith, K. (2007). Empowering school and university-based teacher educators as assessors: School-university cooperation. Educational Research and Evaluation, 73(3), 279-293.

Smith, K. (2010). Assessing the practicum in teacher education: Do we want candidates and mentors to agree? Studies in Educational Evaluation, 36, 36-41.

Wilson, E. K. (2006). The impact of an alternative model of student teacher supervision: Views of the participants. Teaching and Teacher Education, 22, 22-31.

Yarling, J. R., \& Wentz, P. J. (1994). Student teaching case book for supervising teachers and teaching interns. USA: Macmillan Publishing Company. 